\title{
Vehicle Design for Formula SAE 2019 Competition
}

\author{
Ryan Lewis, Mechatronic Engineering, Andriy Belz, Mechatronic Engineering \\ Vaughn College of Aeronautics and Technology, NY, USA \\ Ryan.Lewis2@vaughn.edu,Andriy.Belz@vaughn.edu
}

\begin{abstract}
This project outlines all the details of designing a unique vehicle for the Formula SAE Design competition. A chassis will be designed that can support all the other systems of the vehicle as well as provide some protection for the driver. The chassis will also feature considerations for a custom suspension system that will keep the vehicle a certain distance from the ground and provide for an adequate amount of chamber gain during cornering. A drive train system will be designed featuring a chain drive powered by an inline four cylinder engine with custom designed cooling, air intake, and fuel injection systems. A braking system will also be designed in accordance with the drive train system to ensure that the vehicle can safely come to a stop. This report will outline the process for selecting the optimal chassis design, suspension, braking, and drive train systems such as cooling, air intake, and fuel injection systems.
\end{abstract}

\section{Keywords: Automotive Design, CAD, Analysis}

\section{INTRODUCTION}

The Formula Society of Automotive Engineers (FSAE) competition emphasizes operating performance, cost, and the overall quality of the vehicle. The vehicle will undergo technical inspection, static test events, and dynamic test events. In the inspection, the vehicle is thoroughly examined to make sure that it complies with the technical specifications of the competition to ensure a standard of safety and design. The three static test events provide the judges and inspectors with more information on the costs, presentation, and design of the car. The cost event shows young engineers how the cost of materials will come into play on the job and give them experience designing parts with budget constraints in mind. An added benefit is giving participants insight into the roles of project management and design that they will have to consider in the future. The presentation event aims to have the students explain all the various methods they used in the design and fabrication of the vehicle and improve their presentation abilities. In the design event, inspectors evaluate selected design materials and the vehicle itself. The dynamic events consist of an acceleration test, skid pad test, timed autocross race, endurance, and fuel efficiency test. Acceleration tests the vehicle's maximum speed, autocross tests the overall handling characteristics of the vehicles, the skid pad test evaluates the car's cornering ability on a flat surface with a constant radius, the endurance and efficiency events will test the vehicle's durability and overall fuel consumption.

Digital Object Identifier (DOI):

http://dx.doi.org/10.18687/LACCEI2019.1.1.491

ISBN: 978-0-9993443-6-1 ISSN: 2414-6390

\section{ENGINEERING REQUIREMENTS}

A. Objective

The objective of this project is to design and build a formula-style race car in adherence with good engineering practices and the Formula SAE guidelines. The car should be able to handle predictably in acceleration, deceleration, cornering and any combination of the three states. Additionally the car will need to be able to protect the driver in the event of a rollover. To accomplish these goals, we will need to design a custom chassis, source a suitable engine, and determine the measurement and auxiliary electronic requirements, develop a drivetrain around the chosen components, design a cooling system and optimize each of these systems.

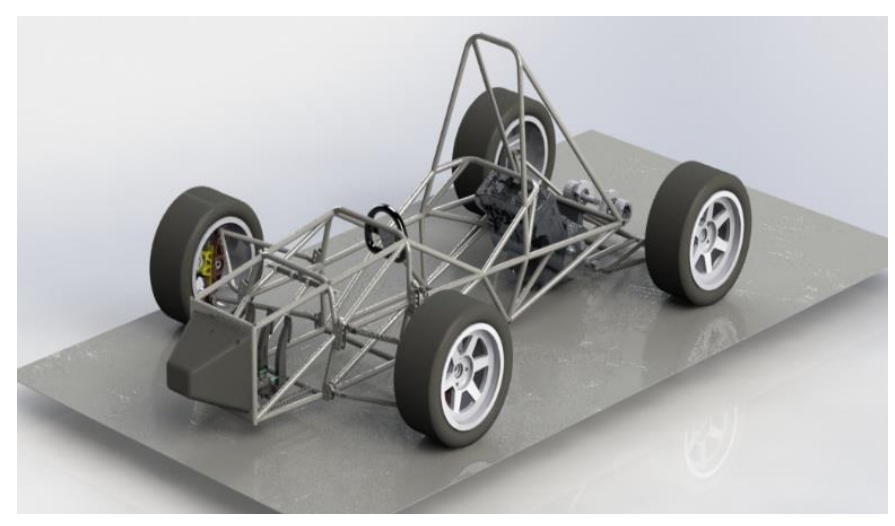

Figure 1: Vehicle CAD Model

\section{B. Performance Requirements}

The car will be designed to travel 75 meters from a complete standstill in the shortest amount of time and withstand a driving endurance test of $22 \mathrm{~km}$ in a closed course while maintaining a fuel efficiency of $3.84 \mathrm{~km} / 1$ or greater per lap.

\section{Chassis Requirements}

The driver must be considered when designing the chassis. The chassis must be able to support a driver between the 5th and 95th percentile of human body sizes for both men and women to ensure that the driver is able to exit quickly in any case. The chassis must also include two main roll hoops that are securely connected to the vehicle and fit a driver in the appropriate body size range. All of the chassis elements excluding the roll hoops must be connected using proper triangulation to ensure that they will protect the driver in the event of a collision or other catastrophic event. This is to ensure that no segments of the chassis are in bending aside from the hoops. Bending in main body elements of the chassis experiencing bending load are more susceptible to crumpling during a collision which could severely injure or kill the driver. The geometry and placement of the components on the

$17^{\text {th }}$ LACCEI International Multi-Conference for Engineering, Education, and Technology: "Industry, Innovation, And Infrastructure for Sustainable Cities and Communities”, 24-26 July 2019, Jamaica. 
structure will be chosen to achieve the best combination of chassis rigidity, weight reduction, and suspension geometry. The engine will function as a load bearing member that is used to attach the rear sub-frame to the chassis. This design will allow the use of less material to hold the suspension and driveline components in the rear resulting in a savings in weight, reduced material cost and greater ease of serviceability.

\section{Drive Train Requirements}

For the purpose of driving a vehicle that weighs roughly $500 \mathrm{lbs}$. with the weight of the driver included an engine with the following characteristics would be ideal. It must be a piston engine using a four-stroke primary heat cycle and have a total combined total displacement which is less than or equal to $710 \mathrm{cc}$ per cycle. Furthermore, all engine systems such as fuel control, delivery and storage, and air intake systems must be contained within the back of the vehicle. The engine must also be economical to obtain and easy to maintain. The most ideal engine for this type of project would be one salvaged from a motorcycle, ATV, or similar small combustion engine sport vehicle. Therefore, the engine from a Honda CBR400F4i motorcycle is ideal. This engine using a chain drive with a scatter shield to prevent damage to bystanders and the vehicle during failure would be enough to reach our acceleration and endurance event goals.

\section{E. Cooling Requirements}

The engine system will require cooling with either air or water as a transfer medium. The CBR600F4i comes with a built-in mechanical coolant pump that circulates into a water jacket to project heat from the engine which will be changed to an electric pump as it allows for more precise control over the flow.

\section{F. Fuel Injection System Requirements}

The fuel injection system for the vehicle needs to be electrically controlled using an ECU to ensure that the proper air-fuel mixture enters the engine and that our vehicle is functioning efficiently.

\section{G. Air Intake System Requirements}

The air intake system needs to be able to control the flow of air into the vehicle and make sure that it enters at the correct frequency as well as allowing air to flow smoothly throughout into the engine.

\section{H. Suspension Requirements}

The design of the suspension system must ensure that the vehicle always maintains the proper distance from the ground and is resistive enough to ensure the vehicle is level at standstill and in a race. The suspension system must have front and rear shock absorbers as well as a minimum wheel travel of at least $50 \mathrm{~mm}$.

\section{Electrical Requirements}

The electrical requirements for a combustion engine are very minimal and most second-hand engines come with the electrical components pre-attached, however these will often need to be rewired or worked with. The changes that were made to the original wiring include removing the lights, kickstand safety switch and the integration of an electric pump and raspberry pi to control the system.

\section{DESIGN}

\section{A1. Chassis}

The chassis is a "space-frame" type design made up of chromoly steel tubes welded together to create an open frame. It has several roll hoops along the body to protect the driver and a detachable rear sub-frame to allow for easy service of the engine and other rear mounted components. Its main functions are to support loads on the vehicle such as the driver and the engine, to give the vehicle its shape, and to provide some protection to the driver.

\section{A2. Chassis Finite Element Analysis}

The design of the chassis was based around considerations to save time, cost, and to reduce the strain on the designers and builders. The chassis was first designed using SolidWorks and simulation tools within the program were used to test the torsional rigidity of several different versions of the chassis to find the version with the least displacement. These tools helped create a chassis configuration that minimized both weight and will keep the driver safe.

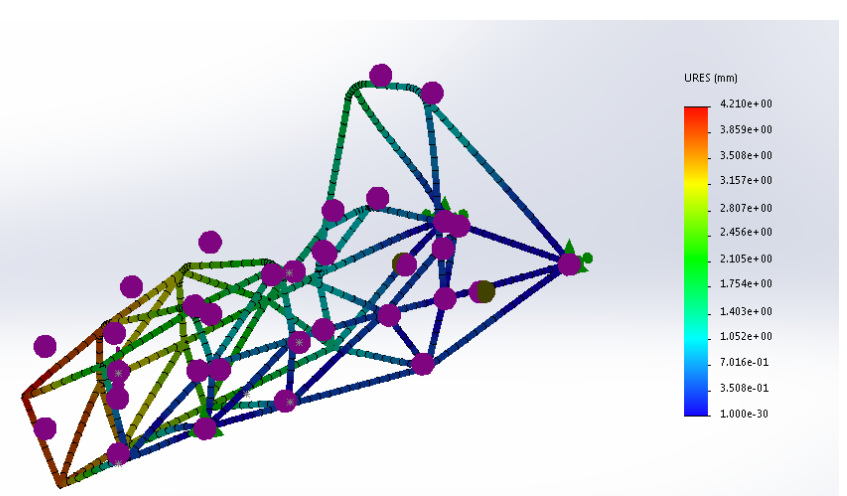

Figure 2: Finite Element Model of the Chassis

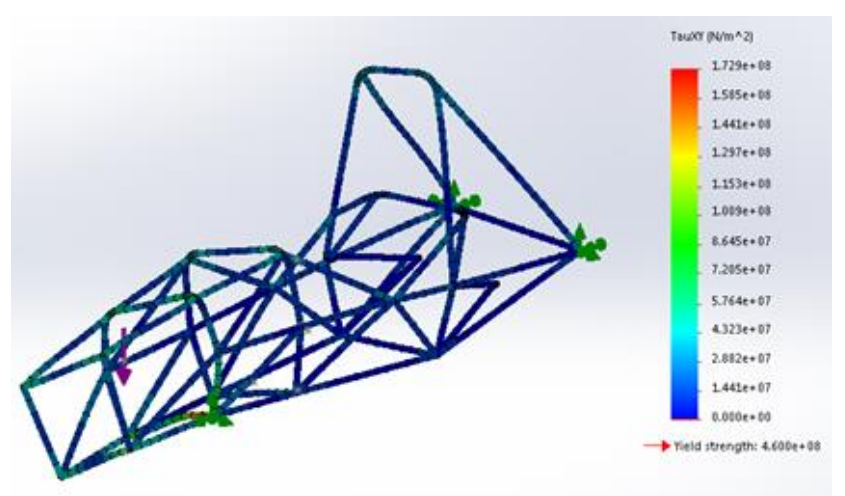

Figure 3. Chassis Shear Force Analysis 


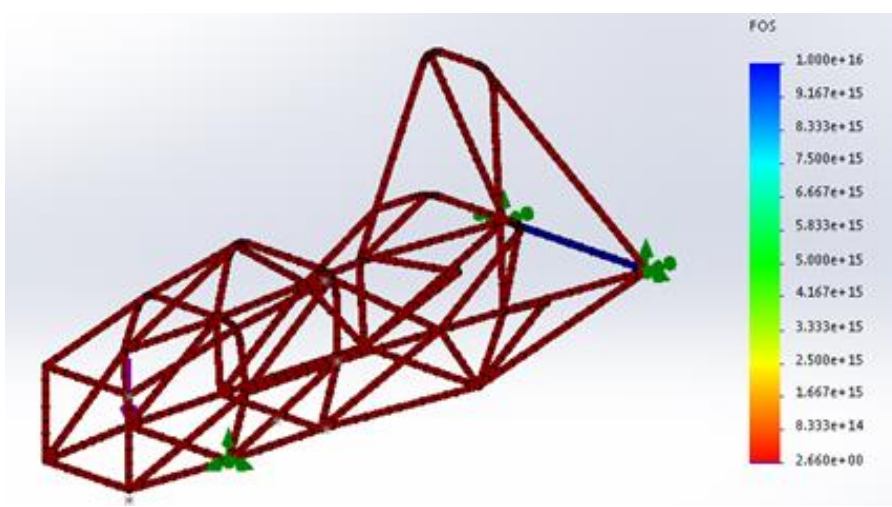

Figure 4. Chassis Model FOS Analysis

Four additional configurations were tested after this analysis to ensure that the maximum displacement produced would be the smallest possible value. This value was found to be 4.210 $\mathrm{mm}$, as seen in Table 1.

TABLE 1

Max Displacement in Different Chassis Versions

\begin{tabular}{|c|c|}
\hline $\begin{array}{c}\text { Chassis } \\
\text { Version }\end{array}$ & $\begin{array}{c}\text { Max. } \\
\text { Displacement } \\
(\text { mm })\end{array}$ \\
\hline V1 & 4.210 \\
\hline V2 & 4.292 \\
\hline V3 & 4.217 \\
\hline V4 & 4.217 \\
\hline
\end{tabular}

A3.

\section{Chassis Materials}

The chassis is made from thin wall chromoly tubing welded together based on the SolidWorks design. They were then welded together so the weldments made a rigid and complete connection at the proper angles specified by the initial design. The welded tubes are 1" diameter 4130 chromoly tubing with 0.049 ", 0.065 " and 0.095 " wall thicknesses. Chromoly is a steel alloy consisting of iron, chromium and molybdenum that is commonly used in the automotive industry for a variety of uses. This material was chosen for the tubing due to its high torsional rigidity, resistance to corrosion, and, high workability with commonly available shop tools. The structure will be made from 0.065 " tubing on either side of the driver and for most of the front bulkhead area covering the driver's legs. Size 0.095" tubing will be used for the hoops directly in front of and above the driver's torso as well as the shoulder bar where the structure will bear most of the load in the event of a rollover. The thinner wall 0.049" tubing was chosen to triangulate the existing members of the chassis after the main crash structure was formed.

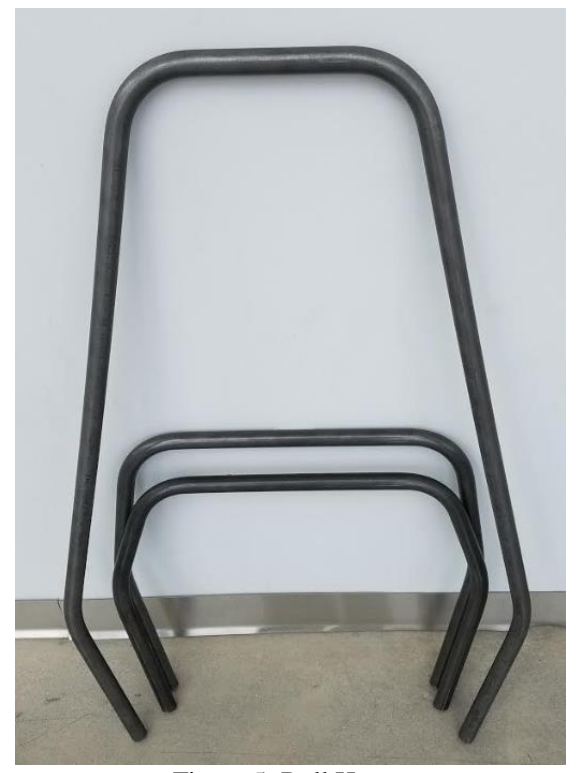

Figure 5: Roll Hoops

\section{A4. Chassis Fabrication}

The method of fabrication chosen for the chassis tubes involved $\mathrm{CNC}$ tube bending and notching. The computerized process created parts which fit closely together with minimal gaps. This provided several benefits such as reducing the weight of the chassis overall by requiring less metal during welding to fill the gaps, creating fewer stress risers in the chassis during loading and allowing the chassis to be more accurately positioned before the welding process. The method of welding involved using a DC TIG welder and welding rods. This filler metal was chosen due to being more ductile than 4130 chromoly as well as being able to alloy properly during welding. It was desirable to use a filler metal that will deform before the base metal in the case of a space frame chassis. This is because it will be experiencing cyclic loading and reduce the likelihood of cracks forming where the base metal and the filler meet.

\section{A5. Jig Construction}

In order to properly assemble all of the different components, the chassis will be constructed using a roughly 4' by 8 " "ladder" platform made from two 6" tall lengths of C channel steel and five cross braces cut from 4" box section tubing. The platform was constructed with the cross braces separated by the same distance as the hoops in the chassis so that they could be more easily supported. The members of the chassis were held using vertical members that were cut out of spare pieces of 0.095 " tubing and tack welded to the chassis jig. After the pieces were roughly aligned and held together with ratchet straps fine adjustments were made by using shims and bending the vertical support tubes. The ladder brace jig will be ensured that all components are properly spaced throughout the building process of the vehicle 


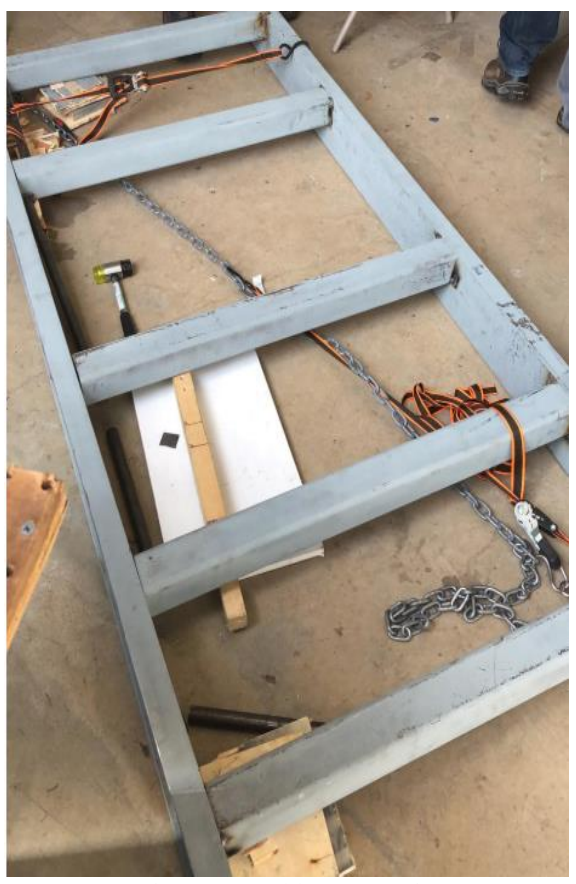

Figure 6: Ladder Brace Jig

\section{A6. Suspension Mounting}

The alignment of he suspension mounting points is critical for the car to track straight under braking, acceleration and while travelling over uneven surfaces. Small changes in the position of the mounting points can have a large effect on the dynamic suspension changes the car experiences. In order to ensure that the chassis was aligned, it was welded in sections with the two main hoops and connecting members forming the nodes for the suspension pickup points assembled first. This was done so the control arm mounting brackets could be bolted to each other and provides a solid foundation to align with the engine and rear sub-frame as the rest of the chassis was assembled.

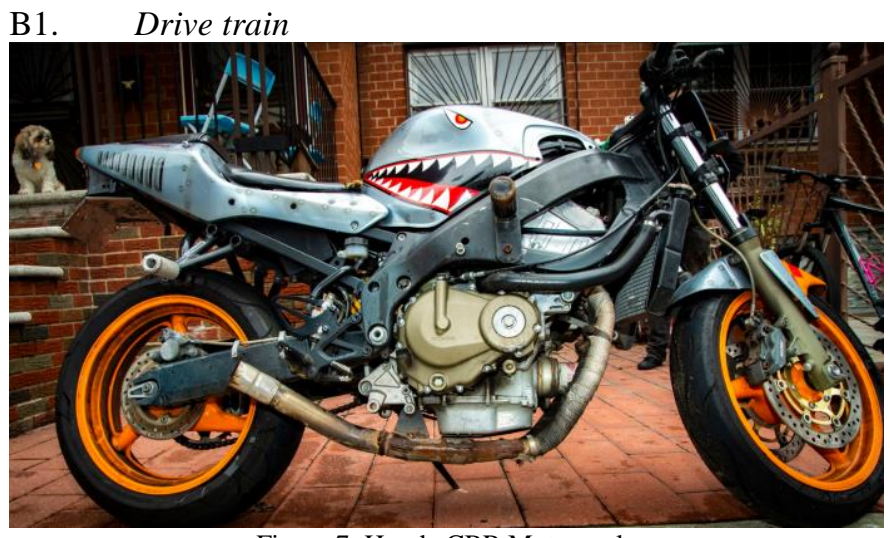

Figure 7: Honda CBR Motorcycle

The main components for the drivetrain are a 2002 Honda CBR600 F4i engine with a custom designed intake, cooling, and fuel injection system. The cooling system utilizes a modified electronically powered water pump. The air intake consists of a custom manifold designed using SolidWorks flow analysis. The fuel injection system consists of an electronic control unit that works with several sensors to precisely control fuel injection into the engine.

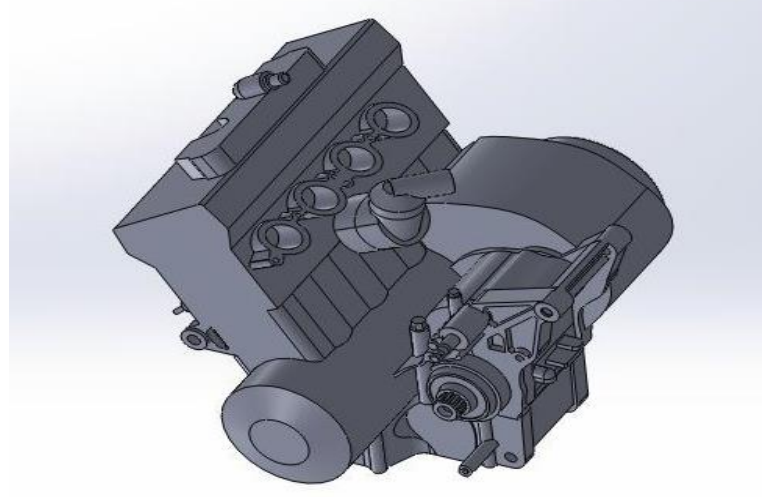

Figure 8: CBR6004Fi Engine

\section{B2. Cooling System}

Replacing the original mechanical water pump with an electric water pump provided several advantages, the main one was the ability to fit a dry sump oil system to the car that will improve both reliability and allow the engine to be lowered, reducing the car's overall center of gravity to improve handling characteristics. Additionally, the electric water pump allows the speed of the coolant flow through the engine to be changed independently of the engine RPM and removal of the original thermostat which contributed to reduced parasitic drivetrain losses. The replacement electric pump for the original mechanical pump was an EBP-40 12-volt motor. The electric pump is controlled by a Raspberry PI $3 \mathrm{~B}$ and motor driver board and responds to aa temperature sensor mounted to the engine.

\section{B3. Fuel Injection System}

The engine uses piggyback-style ECU to control the air-fuel ratio by connecting in-line with the fuel injectors, air temperature and manifold absolute pressure sensors. The ECU will calculate the amount of air entering the engine using the pressure, temperature, and a factory calibrated volumetric efficiency table, which varies its values based on engine load and speed. By modifying the intake and the exhaust, the volumetric efficiency of the engine will be changed. The desired and actual air-fuel ratios will have a significant amount of variance which can be measured using a wideband oxygen sensor in the exhaust. The differences will be compared to calculate a corrected volumetric efficiency table. This will be possible because the fuel injectors output a precise amount of fuel which can be measured and expressed as a function of latency and injector pulse width. Based on the known fuel quantity and the percentage error in the expected/actual air-fuel ratio, the volumetric efficiency table can be modified to account for any lambda errors. By modifying the intake and the exhaust the volumetric efficiency of the engine was optimized for a lower RPM to ensure that the engine is operating within its ideal power band throughout the different events at the competition. This was done by tuning the individual manifold 
runner lengths so that their natural resonant frequency produces either a scavenging or ram air effect at the same frequency as the desired efficient operating frequency. After the volumetric efficiency of the engine was changed the desired and actual airfuel ratios was compared to calculate the new efficiency tables (as a function of RPM and Load). This is possible because the fuel injectors are calibrated from the factory to output a specific amount of fuel for time that they are open and the known fuel quantity/error in air-fuel ratio was used to determine the magnitude of the error between the actual and expected air-fuel ratios.

\section{B4. Intake System}

An intake was designed for the CBR600 motor being used on the car to help optimize its drivability and low-end torque. The main design change was to extend the length of the runners and lower the frequency where the air entering the engine resonated.

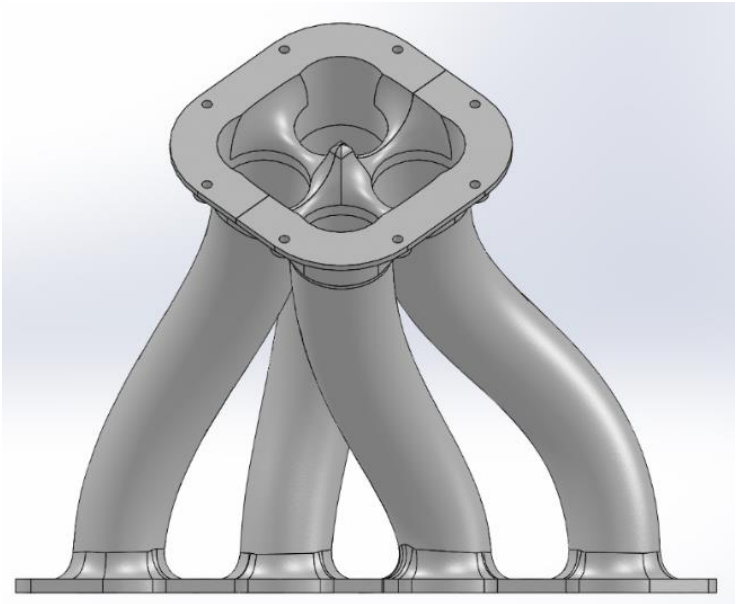

Figure 9: CAD Design of Intake

Wavelength $=\lambda=(4 / 1) * \mathrm{~L}$

Engine intake valve opening frequency $=0.5 *(1 / 60) * \mathrm{RPM}$

Frequency $=$ speed of sound $/$ wavelength $=\left(\frac{314 \mathrm{~m} / \mathrm{s})}{(4 \mathrm{~L}}\right)$

The formulae listed is for the first resonant frequency of a closed tube. Formulae (1), (2), and (3) are not accurate enough to calculate the frequency of the tapered intake runners which are constantly undergoing transient flow conditions. However, with an engine that is constantly changing operating speed, it does serve as a good jumping off point to design an intake which is optimized for the desired RPM range. In a case where the engine is running at a constant speed, it would be much more important to have the resonant frequency of the intake and exhaust runners matched with the frequency at which the valves open and close to produce a more efficient combustion cycle. The intake runners and plenum design were analyzed using SolidWorks flow workbench to view the flow from the inlet to each individual runner and confirm even flow rates across each cylinder for a steady state flow condition. The injector housing was prototyped using an inkjet resin $3 \mathrm{~d}$ printing process to create a dimensionally accurate model to test fit the fuel injectors along with the seals.

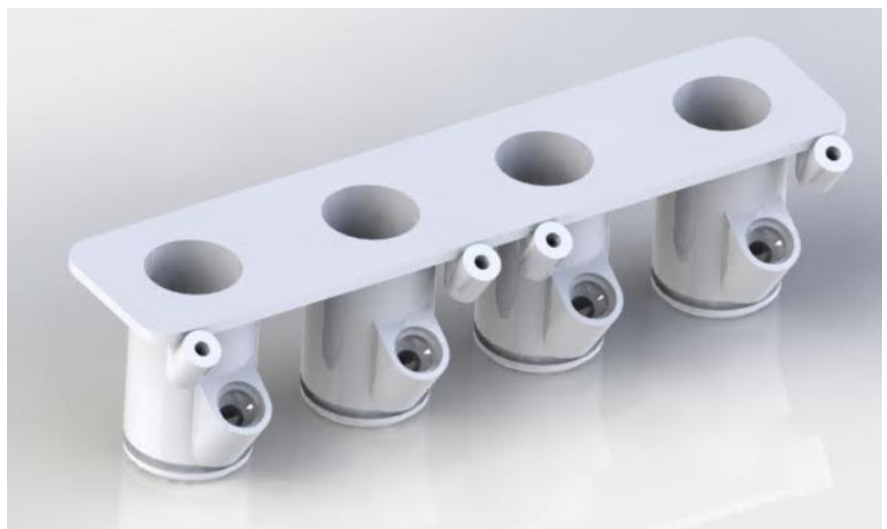

Figure 10: Injector Housing

The initial intake for the car was designed based on a traditional velocity stack with a single throttle body which would allow the tuning of individual cylinders by changing the lengths of each of the trumpets protruding into the intake plenum. At first glance, this type of setup works well, however, upon further examination the flow into each of the cylinders requires a transient fluid analysis to understand the full implications of an intake system. The valve opening events of the cylinders overlap and matching the flow into the cylinders while they operate independently does not accurately reproduce the nature of the flow seen in the intake manifold.

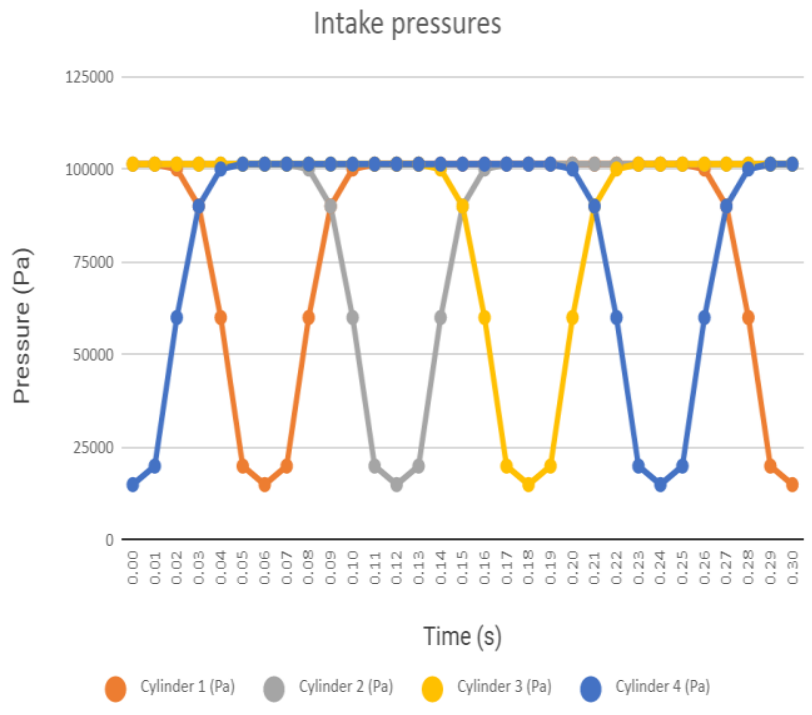

Figure 11: Intake Pressure over Time

As indicated, the first version of the intake utilized a row of linearly distributed velocity stacks feeding air to each cylinder. After the intake was analyzed in SolidWorks, it was found to produce different flow characteristics if the intake event from the prior cylinder was adjacent or separated from the cylinder that currently has its intake valve open. 


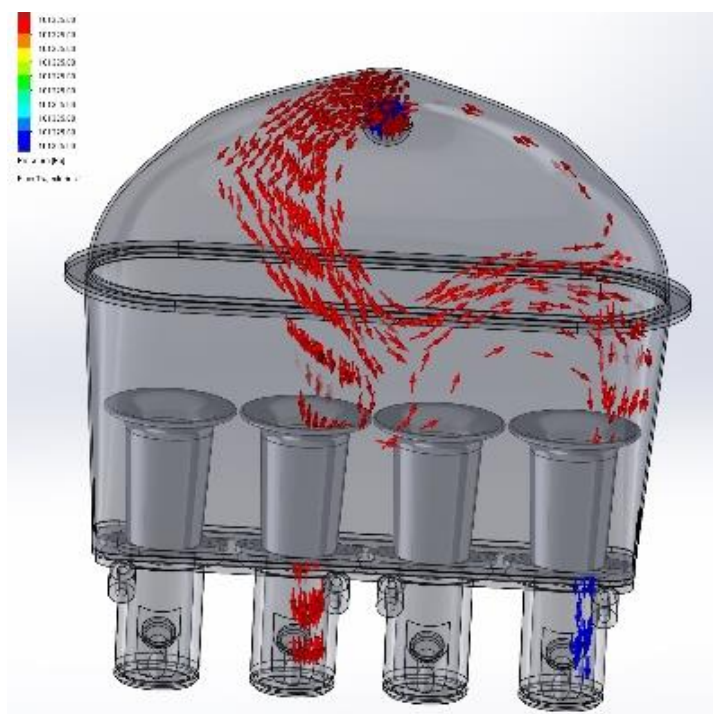

Figure 12: Intake V1. Simulation with Alternate Cylinders

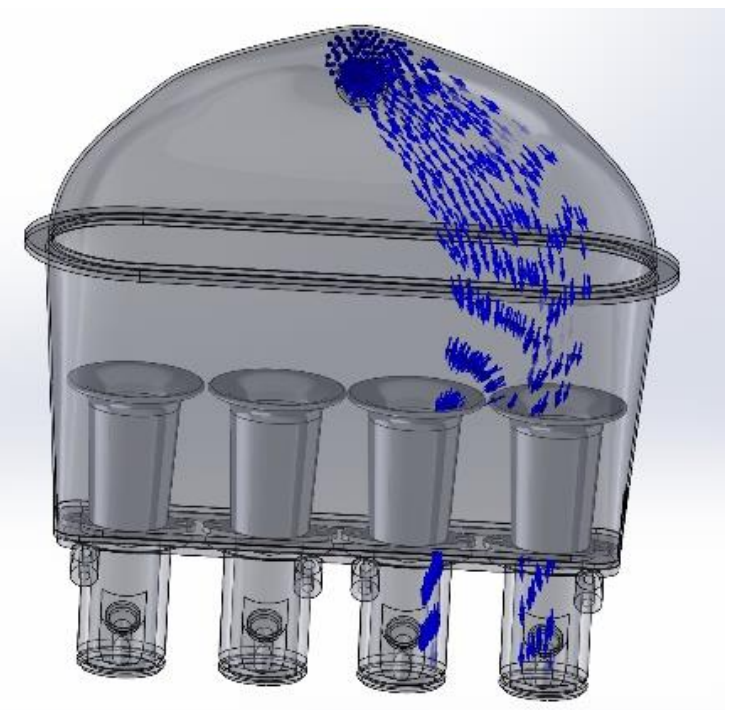

Figure 13: Intake Simulation with Adjacent Cylinders

With this realization, the intake was optimized for the transient and valve overlap conditions and a new manifold and plenum were designed. The runners were arranged so that they would be positioned circularly within the plenum and so that the runners feeding cylinders with overlapping intake strokes were adjacent to each other. In this case, the runners were arranged clockwise in the cylinder order of 1,2,4,3 (the firing order of the engine). Having the runners positioned so that they would be fed air in a counterclockwise position would have produced a mirrored version of the same intake which would have the same flow characteristics.

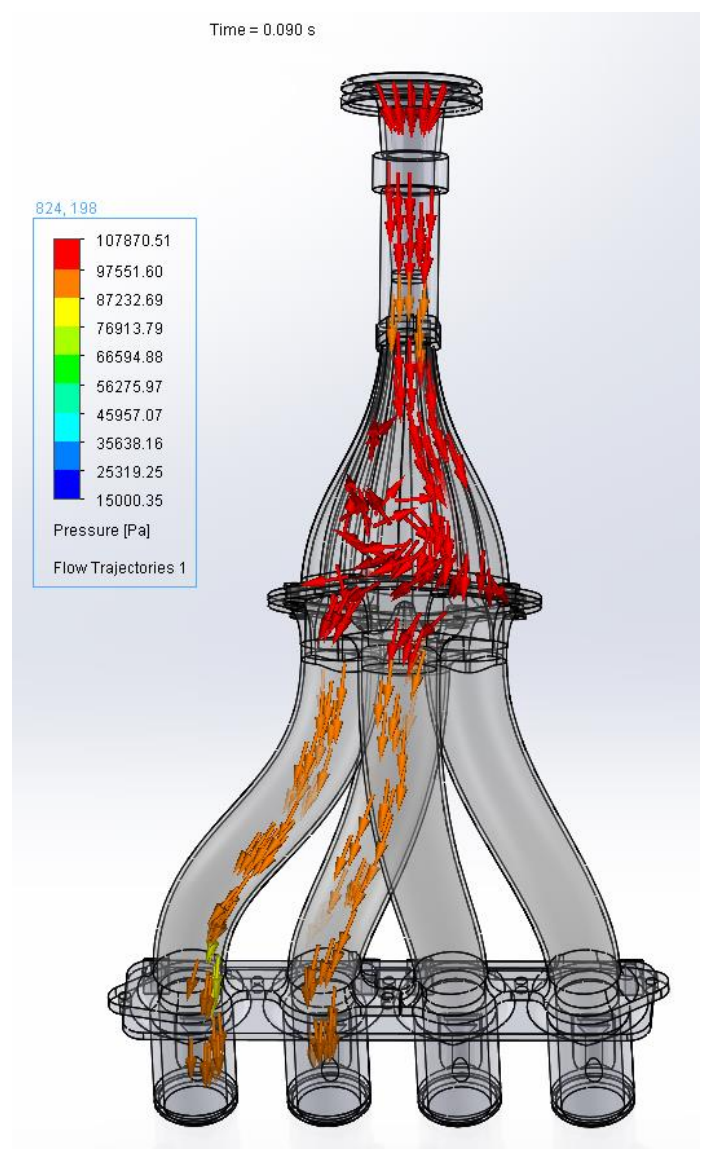

Figure 14: Flow Analysis of Final Intake Design

Knowing that the air would be flowing from one cylinder to the adjacent one as the intake valves open and close the transition between adjacent cylinders was optimized to remove any sharp edges and provide as close to a constant radius of curvature between the cylinders as possible

Both versions of the intake were designed to be produced with a milled aluminum injector housing, $3 \mathrm{~d}$ printed intake runners, $3 \mathrm{~d}$ printed intake plenum and a milled throttle body housing. This design was chosen to allow multiple revisions and spares to be easily made for the runners and plenum, which contain no moving parts, and to allow the injector housing, which will be in contact with fuel, and the throttle body housing to be as robust as possible.

The intake manifold and plenum were designed with chamfers between the flanges and runners to reduce any possible stress concentrations that may occur, and flat surfaces were extruded in locations where bolt holes had been added to allow an even distribution of clamping pressure. The $3 \mathrm{~d}$ print method chosen for the intake was a compound with wax support material. This was found to be the ideal method of manufacture due to the support material being dissolved after printing as opposed to mechanically removed. This leaves less room for error when processing the print and requires less effort to produce the finished product. 


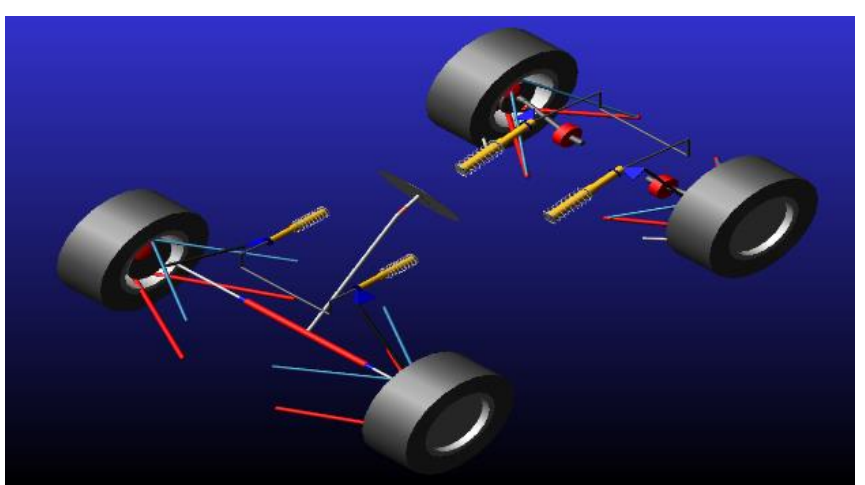

Figure 15: Adam's Car Suspension Model

The front suspension of the car uses a short/long arm setup and the rear suspension system utilizes a Lancaster Link suspension. Lancaster links allow for more camber gain per inch of wheel displacement than it would with separate inboard control arm mounts. Using Lancaster Links for the rear suspension will also compliment the detachable rear sub-frame design by requiring fewer mounting points. The front suspension will also benefit from a short/long arm set up because the geometry of the system provides a camber gain when the wheels are turned while cornering on a track and provides greater grip across the contact surface and minimizes the chance of the car rolling over.

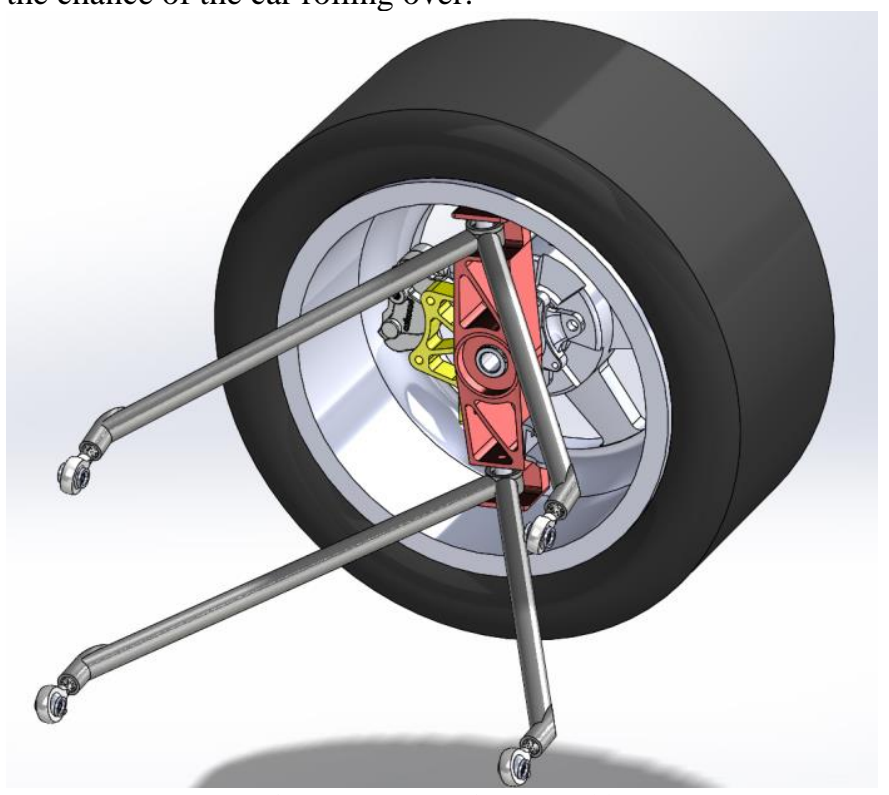

Figure 16: Suspension Assembly

The ideal roll centers were placed at similar vertical heights and as close to the ground as possible to allow for similar induced moments about the roll axis in the front and rear. This was done to allow the car to roll properly and not put unnecessary torsional load on the chassis during hard cornering.

\begin{tabular}{|c|c|c|c|}
\hline & loc_x & loc_y & loc_z \\
\hline fsae_rear_arb.ground.hpl_arb_bend & 1132.0 & -203.2 & 206.4 \\
\hline fsae_front_arb.ground.hpl_arb_bend & -512.0 & -203.2 & 403.4 \\
\hline fsae_front_susp.ground.hpl_BC_axis & -359.6 & -254.0 & 333.0 \\
\hline fsae_rear_susp.ground.hpl_BC_axis & 802.0 & -274.0 & 408.0 \\
\hline fsae_rear_susp.ground.hpl_BC_center & 817.0 & -264.0 & 331.8 \\
\hline fsae_front_susp.ground.hpl_BC_center & -359.6 & -254.0 & 434.6 \\
\hline fsae_front_susp.ground.hpl_damper_inboard & -131.0 & -203.2 & 472.7 \\
\hline fsae_rear_susp.ground.hpl_damper_inboard & 497.0 & -203.2 & 281.0 \\
\hline fsae_front_susp.ground.hpl_damper_outboard & -385.0 & -203.2 & 472.2 \\
\hline fsae_rear_susp.ground.hpl_damper_outboard & 827.2 & -203.2 & 344.5 \\
\hline fsae_rear_susp.ground.hpl_drive_shaft_inr & 1000.0 & -200.66 & 126.06 \\
\hline fsae_rear_arb.ground.hpl_drop_link & 827.2 & -203.2 & 344.5 \\
\hline fsae_front_arb.ground.hpl_drop_link & -385.0 & -203.2 & 472.4 \\
\hline fsae_rear_susp.ground.hpl_lca_front & 776.4 & -180.0 & 63.5 \\
\hline fsae_front_susp.ground.hpl_lca_front & -766.0 & -219.1 & 21.85 \\
\hline fsae_rear_susp.ground.hpl_lca_outer & 1030.4 & -530.0 & 51.6 \\
\hline fsae_front_susp.ground.hpl_Ica_outer & -512.0 & -716.0 & 27.4 \\
\hline fsae_front_susp.ground.hpl_Ica_rear & -258.0 & -219.1 & 21.85 \\
\hline fsae_rear_susp.ground.hpl_lca_rear & 1284.4 & -180.0 & 63.5 \\
\hline fsae_rear_arb.ground.hpl_leaf link & 1132.0 & -203.2 & 308.0 \\
\hline
\end{tabular}

Figure 17: Mounting Point Locations

Based on these constraints, the control arms mounting point heights and distance from the center plane were chosen. The control arms were designed so that of the eight total control arms left and right of the sets would be identical but the top and bottoms are different. This allowed for the same jig to be used to produce control arms for the left and the right side.. The equal length control arms created a unique situation where the upper control arms would need to be mounted rearward of the lower control arms on the chassis. This alignment was used in order to achieve a positive caster angle, improving vehicle stability. After the mounting points for the control arms were chosen, the chassis was modified so the front roll hoop and the hoop behind the front bulkhead were repositioned in order to accommodate the control arms to mount at the chassis nodes.

\section{Braking system}

In order to design the brake system, it was decided to use outboard brakes with each caliper having two pistons. The brake bias was decided to be 70:30 based on maximum deceleration and values found through weight transfer values based on simulations. The rotors were chosen to be the same size in the front and rear so they can be interchangeable. The inside diameter of the rear brake rotor was designed to be slightly larger than the outer diameter of the rear hub for packaging reasons. Subsequently, the outer diameter was chosen so there would be enough width for the brake pads to fully contact the rotor. There were no published values for the coefficient of friction for the brake pads that were acquired, but a value of 0.4 was determined to be expected for a pad of similar material. 


\section{CONCLUSION}

Stopping force generated at tires

○ $\quad \mathrm{F}_{\text {tire }}=500 \mathrm{lbs} \times 1.5 \mathrm{~g}=750 \mathrm{lb}$

○ $\quad F_{\text {front }}$ tires $=0.7 \times 750 \mathrm{lbs}=525 \mathrm{lbs}$

○ $\quad F_{\text {per each front tire }}=\frac{525 \mathrm{lbs}}{2}=262.5 \mathrm{lbs}$

$\circ \quad F_{\text {rear tires }}=0.3 \times 750 \mathrm{lbs}=225 \mathrm{lbs}$

○ $\quad \mathrm{F}_{\text {per each rear tire }}=\frac{225 \mathrm{lbs}}{2}=112.5 \mathrm{lbs}$

Force Ratio between Rotor and Tire

$$
\begin{aligned}
& \text { - } \quad \mathrm{F}_{\text {rotor }} * \mathrm{R}_{\text {rotor }}=\mathrm{F}_{\text {tire }} \times \mathrm{R}_{\text {tire }} \\
& \text { O } \quad F_{\text {rotor }}=F_{\text {tire }} \times \frac{16.25^{\prime \prime}}{8.5^{\prime \prime}}=F_{\text {tire }} \times 1.912 \\
& \text { ○ F front rotor } 262.5 \times 1.912=501.9 \mathrm{lbs} \\
& \text { - Frear rotor }=112.5 \mathrm{lbs} \times 1.912=215.1 \mathrm{lbs}
\end{aligned}
$$

Determining line pressure

$$
\begin{array}{ll}
\bigcirc & F_{\text {front clamping }}=\frac{F_{\text {front rotor }}}{\mu_{\mathrm{f} \text { brakes }}}=\frac{501.9 \mathrm{lbs}}{0.4}=1255 \mathrm{lbs} \\
\bigcirc & F_{\text {rear clamping }}=\frac{F_{\text {Rear rotor }}}{\mu_{\text {f brakes }}}=\frac{215.1 \mathrm{lbs}}{0.4}=538 \mathrm{lbs} \\
\bigcirc & P_{\text {line front }}=\frac{F_{\text {front clamping }}}{A_{\text {front pistons }}}=\frac{1255 \mathrm{lbs}}{2 \times \frac{\pi}{4} \times(1.125 \mathrm{in})^{2}}=631 \mathrm{psi} \\
& P_{\text {line rear }}=\frac{F_{\text {rearclamping }}}{A_{\text {rear pistons }}}=\frac{538 \mathrm{llbs}}{2 \times \frac{\pi}{4} \times(1 \mathrm{in})^{2}}=343 \mathrm{psi}
\end{array}
$$

Calculating master cylinder piston size

$$
\begin{aligned}
& \mathrm{F}_{\text {front } \mathrm{MC}}+\mathrm{F}_{\text {rear } \mathrm{MC}}=5.5 \times 60 \mathrm{lbs} \\
& \text { Ffront } \mathrm{MC}=\mathrm{F}_{\text {rear }} \mathrm{MC} \\
& \mathrm{F}_{\text {front } \mathrm{MC}}=\mathrm{F}_{\text {rear } \mathrm{MC}}=165 \mathrm{lbs} \\
& P \text { line front } \times A_{\text {front }} \mathrm{MC}=\mathrm{P}_{\text {line rear }} \times \mathrm{A}_{\text {rear } \mathrm{MC}} \\
& \frac{P_{\text {line front }}}{P_{\text {line rear }}}=\frac{\frac{\pi}{4}\left(D_{\text {rear MC }}\right)^{2}}{\frac{\pi}{4}\left(D_{\text {front MC }}\right)^{2}} \\
& \text { MC Ratio }=\frac{D_{\text {rear MC })}}{\left.D_{\text {front MC }}\right)}=\sqrt{\frac{P_{\text {line front }}}{\text { Pline rear }}}=\sqrt{\frac{631}{343}}=1.36 \\
& \mathrm{~A}_{\text {front } \mathrm{MC}}=\frac{\text { Ffront MC }}{\text { Pline front }}=\frac{165 \mathrm{lbs}}{631 \mathrm{psi}}=0.26 \mathrm{in}^{2} \\
& \mathrm{~F}_{\text {ront } \mathrm{MC}}=4 \times \mathrm{A}_{\text {front } \mathrm{MC}}=0.58 \\
& \text { The master cylinder for the front will be is } 5 / 8 \text { " } \\
& \mathrm{D}_{\text {rear } \mathrm{MC}}=\mathrm{D}_{\text {front } \mathrm{MC}} * 1.36=0.625^{\prime \prime} \times 1.36=0.85 \\
& \text { The master cylinder for the rear will be } 7 / 8 \text { " }
\end{aligned}
$$

The tires produce a maximum acceleration/ deceleration of $1.5 \mathrm{~g}$. The calipers available from our supplier could be purchased with either a 1 " or $11 / 8$ " piston diameter. Knowing that the front wheels require more braking force than the rear, the larger piston calipers were selected for the front and the smaller size for the rear. With the caliper piston diameters and required stopping force determined, the master cylinders were selected. A brake balance bar was implemented to allow for the brake bias to be adjusted. This allowed for more braking force in the rear when there is less traction available. Initially, a pedal braking force of 60lbs was chosen as it is half the weight of the team's lightest driver. However, small enough master cylinder diameters were not readily available, and the closest size was chosen for the smaller of the two master cylinders.

\section{E. Modifications to the electrical system}

The electrical systems that came attached to the 2002 Honda CBR600 $4 \mathrm{i}$ engine needed to be rewired to fit to all the subsystems that were not originally designed to be used in conjunction. To this end, many different components were removed or rerouted to provide power to subsystems and to fit with the different positioning of components. The result of modifications on the electrical systems was the removal of the lights wiring assembly and the kickstand safety switch.
The vehicle designed had many unique features. It utilized a custom designed chassis that was tested using SolidWorks' finite element analysis tools to ensure that it was lightweight and rigid. The engine of the vehicle is a CBR6004Fi which features a modified PID controlled electric motor, for water cooling, a custom designed intake for optimized air flow and reduction in pulse magnitude during valve openings, a custom brake system, and a Lancaster link suspension.

\section{ACKNOWLEDGMENTS}

The authors would like to thank the President of Vaughn College of Aeronautics and Technology, Dr. Sharon DeVivo, The chair of the Engineering Department, Dr. Hossein Rahemi, Professor Miguel Bustamante, and our advisor Professor Douglas Jahnke for their continued support

[1] FSAE 2019 Rules, SAE,

\section{REFERENCES}

https://www.fsaeonline.com/cdsweb/gen/DownloadDocument.aspx?Do cumentID=64b861c2-980a-40fc-aa88-6a80c43a8540

[2] Solidworks 2018, Static Load Study Analysis

[3] F. P. Beer, Mechanics of materials. New York, NY: McGraw-Hill

Education, 2020

$1^{\text {th }}$ LACCEI International Multi-Conference for Engineering, Education, and Technology: "Industry, Innovation, And 